\title{
Modeling, Analysis, and Simulation of Auxiliary Bearing for High-speed Rotating Machinery
}

\author{
C. Bambang Dwi Kuncoro, ${ }^{1}$ Rafael Oscar, ${ }^{1}$ Chung-Che Liu, ${ }^{2}$ \\ Chao-Yun Chen, ${ }^{2}$ Kuo-Shu Hung, ${ }^{2}$ and Yean-Der Kuan ${ }^{1 *}$ \\ ${ }^{1}$ Department of Refrigeration, Air Conditioning and Energy Engineering, National Chin-Yi University of \\ Technology, No. 57, Sec. 2, Zhongshan Rd., Taiping Dist., Taichung City 41170, Taiwan \\ ${ }^{2}$ Green Energy and Environment Research Laboratories, Industrial Technology Research Institute, \\ 195, Sec. 4, Chung Hsing Rd., Chutung, Hsinchu 31040, Taiwan
}

(Received May 2, 2021; accepted September 10, 2021)

Keywords: rotor, contact force, magnetic bearing, finite element, touchdown

An active magnetic bearing (AMB) revolutionizes rotating machinery applications by eliminating the friction problem of conventional contact bearings and the need for lubrication. Supporting equipment is necessary as a countermeasure in case the AMB fails to operate or its magnetic field decreases in power, causing the rotor to fall, known as a dropdown event. An auxiliary bearing is necessary to prevent direct contact between the rotor and the AMB, as the AMB itself is not designed to be durable against impact or rotational friction. Therefore, the auxiliary bearing is designed to absorb and withstand the contact force. The aim of this study is to find the best design for the auxiliary bearing to decrease the erratic and whirling motion of the rotor after contact. The nonlubricated Hertzian contact model is used to analyze the rotor drop dynamics, and the finite element method is used as the basis of the flexible rotor model. A simulation is carried out using MATLAB software. The simulation reveals the rotor orbit, rotor response, and contact force, provides a comparison of the stiffness support and damping support effects, and also predicts the bearing life to provide a new approach for bearing selection. The results of this study provide the relevant information for selecting the material of the auxiliary bearing with the most appropriate damping and stiffness properties to disperse the contact force during a rotor drop event.

\section{Introduction}

An active magnetic bearing (AMB) is one of the several industrial breakthroughs that have changed the traditional perception of rotating machinery. An AMB can support a high-speed rotor without any mechanical friction or lubrication and enables control of the rotor position and induced vibration by adjusting the support and damping coefficient of the electromagnetic bearing. ${ }^{(1)}$ However, in the case of unpredictable events such as power failure and magnetic failure, the AMB can lose its ability to support the rotor. The shaft will then fall and might collide with the AMB. To avoid this potential situation, a countermeasure is necessary. A 
touchdown bearing can be used as such a countermeasure. Touchdown bearings have multiple names such as retainer bearings, auxiliary bearings, and catcher bearings. Touchdown bearings are an important part of any high-speed magnetic bearing system and can prevent direct contact between the rotor and AMB during a rotor drop event by providing a landing pad for the rotor, thus preventing catastrophic system failure. ${ }^{(2)}$ From an economic viewpoint, an AMB can reduce the operating cost as it has a bearing loss 5 to 20 times less than that of conventional ball or journal bearings at high operating speeds. An AMB also has a lower maintenance cost and a longer lifetime than conventional bearings and its reliability under severe conditions has been demonstrated. ${ }^{(3)}$

When an AMB undergoes partial or total failure due to a loss of power, damaged coil, or another failure mechanism, it loses its ability to stably support the rotor. The rotor will then fall or drop onto the retainer bearing or magnetic bearing if a touchdown bearing is not present. An inadequate touchdown bearing design could be dangerous, even if not fatal, for the magnetic bearing system. Sun et al. presented a detailed bearing model for a magnetic suspension auxiliary device. Their study showed that the friction coefficient, support damping, and side loads are critical parameters in retainer bearing design as they can prevent backward whirl or super whirl. This result is in agreement with the study of Wilkes et al., in which a whirling phenomenon was generated by the friction between the journal bearing and the axial face of the catcher bearing. ${ }^{(2)}$ Cao et al. presented a detailed formulation for the nonlinear transient analysis of a rotor dropdown event. ${ }^{(4)}$ In the dropdown situation, when the rotor drops from the magnetic bearing to the touchdown bearing, the design parameters of the touchdown bearing have a significant influence on the rotor behavior. The rotor dynamics can be simulated to determine the rotor response and behavior. Many researchers have studied touchdown bearing design parameters to determine the rotor response and behavior. Various parameters of the touchdown bearing design, such as the friction coefficient, mass of unbalance, stiffness, and damping support coefficient, have been studied using simulation models. $(5,6)$

The rotor in an AMB is levitated by providing a sufficient electromagnetic force. The control equipment for an AMB consists of four parts: a sensor to measure the rotor displacement from its reference point, a power amplifier to convert the control signal to the control current, an electromagnetic field generator to generate the electromagnetic field relative to the control current, and a microprocessor to derive the control signal from the sensory signal. With its interconnection of mechanical and electronic components and the use of software as the interface with the machine, the AMB represents a typical product of mechatronics. ${ }^{(7)}$ There are two methods of control that are widely used for AMB systems: fuzzy logic and proportional, integral, derivative (PID) control.

In this study, the effects of damping support and stiffness support are also evaluated. The damping support and stiffness support in this study are provided by a tolerance ring. This is a circular device made from thin spring steel strips that have corrugations in their surface. The strips are made into a ring shape but there is a gap between the strips. The corrugations themselves may face inwards or outwards depending on the application. The main function of the tolerance ring is as a fastener between two circular bodies. Tolerance rings have damping and stiffness properties dependent on their shape and design. Therefore, tolerance rings can also 
be used as thermal expansion compensation devices and to absorb vibrations and compensate for misalignment.

In this study, which is based on the work of Chen et al., the effects of the stiffness and damping coefficient of a tolerance ring on the rotor response and the magnitude of the contact force are evaluated. ${ }^{(8)}$ The tolerance ring in this study is assumed to be in the AN configuration, which means that it is placed between the auxiliary bearing and the compressor shell. The stiffness coefficient of a tolerance ring is related to its geometrical structure and material properties.

The failure of AMBs generates highly nonlinear behavior or an interaction between the rotor and touchdown bearings. ${ }^{(9-12)}$ Thus, the interaction between the rotor and the touchdown bearings must be simulated to clarify the uncertainty encountered during a dropdown event (AMB failure). The uncertainty encountered during AMB failure affects the rotor behavior. Therefore, we present a dynamic simulation of the rotor to identify its response and behavior during a dropdown event. The rotor behavior can be seen via the rotor response or rotor motion, meaning that the rotor must be modeled in the simulation. Some researchers have modeled the rotor as a rigid rotor in their simulation. ${ }^{(13,14)}$ However, in this study, the rotor is modeled as a flexible rotor using the finite element method. The effects of the rotor speed and the touchdown bearing design (with or without damping support and stiffness support) are examined to analyze the rotor behavior on the basis of its orbit and response and the contact force. The approach in this study can be applied to further improve the overall AMB design process (i.e., mechanical, material selection, and control system aspects).

\section{Materials and Methods}

\subsection{Mathematical model of rotor drop}

The AMB system has different equations of motion before and after the dropdown event. Before the dropdown event, the rotor is supported by the AMB. However, when the AMB power is lost in the system, the rotor drops onto the touchdown bearing because the AMB cannot support the rotor stably. Figure 1 illustrates the rotor model, where $K_{c}$ is the contact stiffness that occurs when there is contact between the shaft and the inner race bearing. $K_{b}$ and $C_{b}$ are the stiffness and damping of the auxiliary bearing, and $K_{s}$ and $C_{s}$ are the stiffness and damping support, located outside the outer races if they exist, respectively.

Finally, considering the external forces acting on the rotor, which include the contact force $\left(F_{c}\right)$, touchdown bearing force $\left(F_{b}\right)$, unbalance force $\left(F_{u}\right)$, and gravity force $\left(F_{g}\right)$, the general dynamic equation of motion of the rotor after the dropdown event is expressed as

$$
M \ddot{q}+(C+\omega G) \dot{q}+K q=F_{c}+F_{b}+F_{u}+F_{g}
$$

where $M$ is the mass matrix, $C$ is the damping matrix, $G$ is the gyroscopic matrix, $K$ is the stiffness matrix, $\omega$ is the rotation speed, and $q$ is the displacement vector. 




Fig. 1. Rotor model.

\subsubsection{Contact force model}

When the rotor drops onto the auxiliary bearing, there will be contact between the shaft and the auxiliary bearing (inner race) because of the change in the clearance. This is called the auxiliary bearing gap. The air gap for the auxiliary bearing is typically half of the air gap of the AMB system. Therefore, when contact occurs, it generates a contact force. The following contact force model used in this study is taken from Liu et al.:(10)

$$
\begin{aligned}
& F_{c x 1,2}=F_{n 1,2} \cos \psi_{1,2}-F_{t 1,2} \sin \psi_{1,2}, \\
& F_{c y 1,2}=F_{n 1,2} \sin \psi_{1,2}+F_{t 1,2} \cos \psi_{1,2},
\end{aligned}
$$

where $F_{n}$ is the normal force and $F_{t}$ is the friction force, which acts perpendicular to the normal force as shown in Fig. 2.

From Fig. 2, the contact angle between the shaft and the inner race bearing can be obtained as follows:

$$
\psi_{1,2}=\tan ^{-1}\left(\frac{Y_{1,2}}{X_{1,2}}\right)
$$

where subscripts 1 and 2 represent the front and rear auxiliary bearings, respectively.

The normal contact force $\left(F_{n}\right)$ and friction force $\left(F_{t}\right)$ are then obtained using

$$
\left\|F_{n 1,2}\right\|=\left\{\begin{array}{cc}
\frac{\pi}{2} \delta_{r 1,2} E L \sqrt{\frac{\delta_{r 1,2}}{2\left(\left(R_{i}-R_{S}\right)+\delta_{r 1,2}\right)}} & \delta_{r 1,2}>0, \\
0 & \delta_{r 1,2} \leq 0,
\end{array}\right.
$$




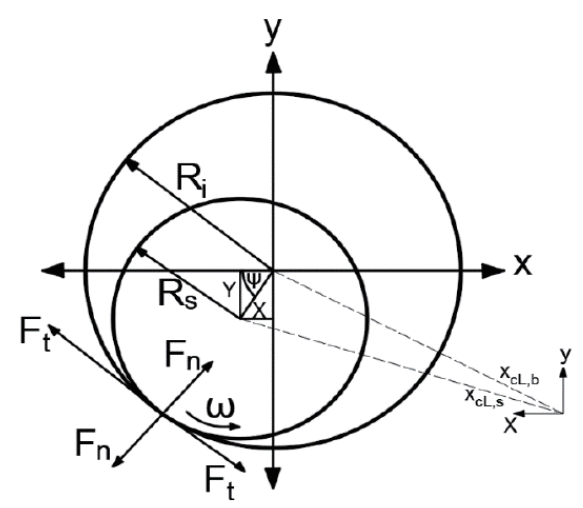

Fig. 2. Shaft-inner-race contact model.

where $\delta_{r}$ is the shaft/race deflection, which is given by

$$
\delta_{r 1,2}=\sqrt{X_{1,2}^{2}+Y_{1,2}^{2}}-\left(R_{i}-R_{s}\right)
$$

Here, $X$ and $Y$ are the coordinates of the shaft center, where $R_{i}$ and $R_{S}$ are the radii of the inner race and the shaft, respectively. $E$ is the Young's modulus of the shaft and $L$ is the contact length.

If contact occurs, the normal force line of the action will be collinear with $x\left(b_{s}\right)$. The direction of the normal force acting on the rotor will be opposite to that of $x\left(b_{s}\right)$. A unit vector $\hat{c}_{n}$ pointing in the normal direction to the force exerted on the rotor can be obtained as

$$
\hat{c}_{n}=-\frac{x_{c L, s}-x_{c L, b}}{\left\|x_{c L, s}-x_{c L, b}\right\|} .
$$

Considering the value of $\hat{c}_{n}$, the normal force is completely determined as

$$
F_{n 1,2}=\left\|F_{n 1,2}\right\| \hat{c}_{n} .
$$

When the rotor and auxiliary bearing are in contact, the auxiliary bearing speed will increase up to the shaft speed, whereas the shaft speed will decrease. These conditions will be affected by the velocity of both surfaces (inner race surface velocity and shaft surface velocity), which can determine the friction coefficient $\left(\mu_{r}\right)$ used to calculate the friction force as follows:

$$
\mu_{r}=\left\{\begin{array}{llr}
\mu_{d}, & v_{s}>v_{i} & (\text { kinetic }), \\
\mu_{s}, & v_{s}=v_{i} & (\text { static }), \\
-\mu_{d}, & v_{s}<v_{i} & (\text { kinetic }),
\end{array}\right.
$$

where the inner race velocity $\left(v_{i}\right)$ and shaft velocity $\left(v_{s}\right)$ can be obtained using 


$$
\begin{aligned}
& v_{i}=\left(\omega_{i} \times R_{i}\right), \\
& v_{s}=\left(\omega_{s} \times R_{S}\right) .
\end{aligned}
$$

Considering the unit vector in the direction of the frictional force, the equation of the friction force $\left(F_{t 1,2}\right)$ is expressed as

$$
\begin{gathered}
F_{t 1,2}=\mu_{r}\left\|F_{n 1,2}\right\| \hat{c}_{t}, \\
\hat{c}_{t}=-\frac{v_{i}-v_{s}}{\left\|v_{i}-v_{s}\right\|} .
\end{gathered}
$$

\subsubsection{Contact force of touchdown bearing}

A system that uses an AMB must be equipped with touchdown bearings as auxiliary bearings. There are two types of touchdown bearing: ball bearings and sleeve bearings. Ball bearings are more commonly used than sleeve bearings. Ball bearings have some advantages over sleeve bearings: as rolling elements, ball bearings have low friction, a compact size, and unlubricated operation.

A ball bearing consists of a number of moving parts. For each ball bearing, there is a normal compressive force, a centrifugal force, and gyroscopic moment. However, in this study, the touchdown bearings are modeled by neglecting their centrifugal force and gyroscopic moment. Some other researchers have also neglected these forces to reduce the simulation time. When both forces are neglected, the following equation can be used in the direct method:

$$
Q_{j}=k_{r b} \delta_{j}^{3 / 2}
$$

The total deformation $\left(\delta_{j}\right)$ and total stiffness $\left(k_{r b}\right)$ of the inner and outer ball raceways can be determined using the Hertzian contact stiffness. ${ }^{(15)} k_{i}$ and $k_{o}$ are the stiffnesses of the inner and outer ball bearing raceways, respectively, which depend on the geometric and material properties of the ball and raceways and can be determined as follows:

$$
k_{r b}=\left[\frac{1}{\left(\frac{1}{k_{i}}\right)^{2 / 3}+\left(\frac{1}{k_{o}}\right)^{2 / 3}}\right]^{3 / 2},
$$




$$
k_{i, o}=\frac{2^{2.5}}{3\left(\frac{\left(1-v_{i, o}^{2}\right)}{E_{i, o}}+\frac{\left(1-v_{b}^{2}\right)}{E_{b}}\right)\left(\delta^{*}\right)^{1.5} \sqrt{\sum \rho_{i, o}}} .
$$

Here, $v_{i, o}$ is the Poisson ratio of the inner and outer raceways, $v_{b}$ is the Poisson ratio of the ball in the bearing, $E_{i, o}$ is the Young's modulus of the inner and outer raceways, $E_{b}$ is the Young's modulus of the ball of the bearing, and $\sum \rho_{i, o}$ is the sum of the inner and outer raceway curvatures.

The parameter $\left(\delta^{*}\right)$ is a function of the curvature difference $F_{(\rho)}$, and the relationship between both values is given in Table 6 of the handbook of Harris and Kotzalas. ${ }^{(16)}$

$$
\begin{gathered}
F_{(\rho) i}=\frac{\frac{1}{f_{i}}+\frac{2 \gamma}{1 \pm \gamma}}{4-\frac{1}{f_{i}}+\frac{2 \gamma}{1 \pm \gamma}} \\
\sum \rho_{i}=\frac{1}{D_{b}}\left(4-\frac{1}{f_{i}} \pm \frac{2 \gamma}{1-\gamma}\right)
\end{gathered}
$$

Finally, referring to Karkkainen et al., ${ }^{(17)}$ the resultant auxiliary bearing forces applied to the shaft in the $X$ and $Y$ directions are as follows:

$$
\begin{aligned}
& F_{b x}=-\sum_{j=1}^{z} Q_{j} \cos \theta_{j}, \\
& F_{b y}=-\sum_{j=1}^{z} Q_{j} \sin \theta_{j} .
\end{aligned}
$$

\subsubsection{Stiffness support and damping support}

The original design of the touchdown bearing is improved by adding support components such as damping support $\left(C_{s}\right)$ and stiffness support $\left(K_{s}\right)$. Figure 3 illustrates the additional damping support and stiffness support added to the original design of the touchdown bearing.

The stiffness support value can be calculated using the following formula given by Smith: ${ }^{(18)}$

$$
K_{\text {spring }}=4.8 \times\left(E_{\text {spring }}\right) \times(w) \times\left(\frac{t}{p}\right)^{3}
$$




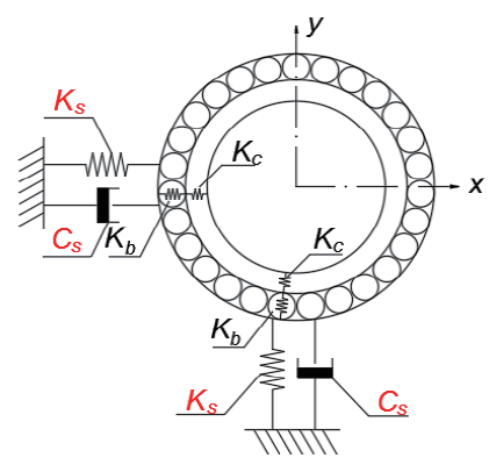

(a)
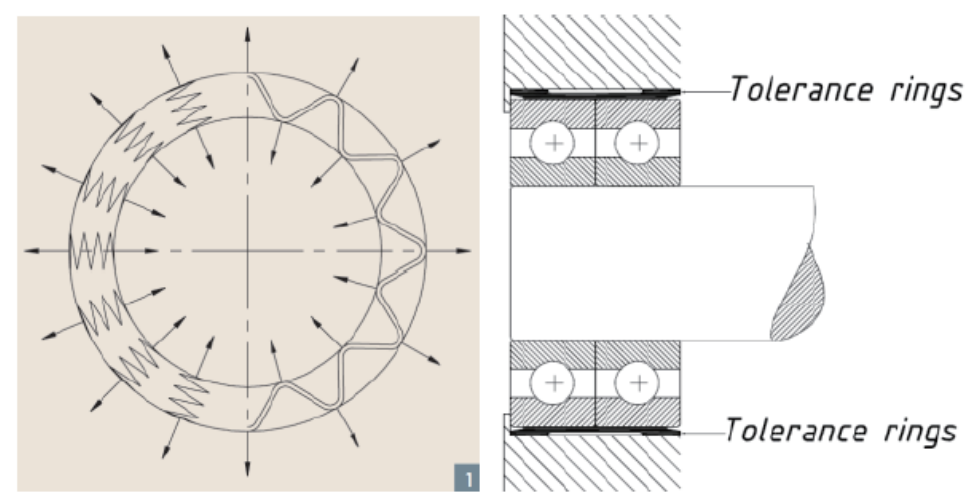

(b)

Fig. 3. (Color online) Design with damping support and stiffness support: (a) ball bearing with damping support and stiffness support and (b) placement of the ball bearing stiffness support and damping support.

where $E_{\text {spring }}$ is the Young's modulus of the material, $w$ is the width, $t$ is the thickness, and $p$ is the wave pitch. The damping support value depends on the stiffness as follows [taken from $\left.\mathrm{RaO}^{(19)}\right]$ :

$$
C_{s}=\zeta \cdot 2 \sqrt{K_{s} m}
$$

where $\zeta$ is the damping ratio of the material, $K_{S}$ is the stiffness support, and $m$ is the mass of the material.

\subsubsection{Effect of axial force}

During the rotor dropdown event, the touchdown bearing must withstand the load not only from the lateral direction but also from the axial direction. Whereas the load from the lateral direction is generated by the external force, the load from the axial direction is generated from the thrust of the working fluid on the impeller. According to Ref. 19, the basic parameters determining the axial force are the geometrical dimensions of the impeller and the seal clearances, in addition to the balance piston geometry and the operating conditions. As mentioned above, the resultant force is strongly dependent on the pressure, mass flow rate, and temperature at the inlet and outlet of each impeller.

There are several factors that can affect the thrust force in the axial direction. The factors that are considered in this study are the force generated from the movement of the fluid against the impeller surface and the force of the fluid due to the pressure difference. The thermodynamical force factor is neglected because it is beyond the scope of this study. The affecting forces are shown in Fig. 4.

The thrust force acting on a single impeller can be written as

$$
F_{\text {ax, fluid }}=F_{\text {st }, \text { in }}+F_{\text {sh }}+F_{\text {mom }}-F_{h}-F_{p i s},
$$




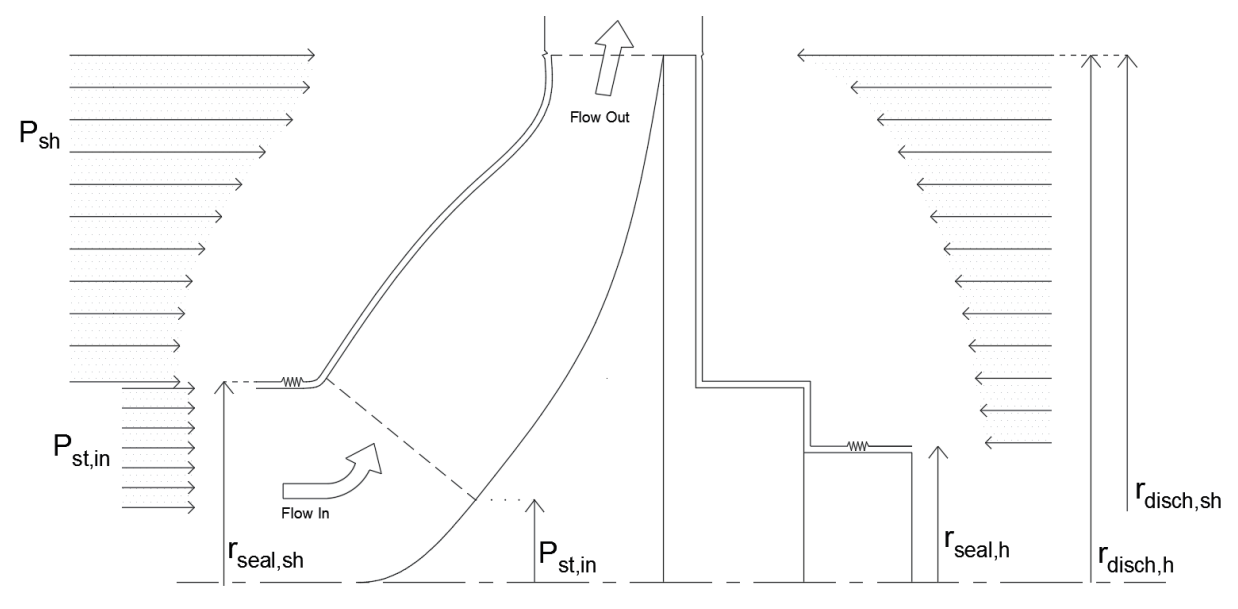

Fig. 4. Thrust force acting on a single impeller.

Here, $F_{s t, i n}$ is the static force acting on the impeller inlet, $F_{s h}$ is the force due to the fluid pressure difference on the shroud surface, $F_{h}$ is the force due to the fluid pressure difference on the hub surface, $F_{m o m}$ is the force due to the momentum of gas acting on the impeller surface, and $F_{p i s}$ is the force on the balance piston.

The most difficult forces to estimate are $F_{s h}$ and $F_{h}$, which are derived from the flow fluid dynamics of the shroud and hub, respectively. These two forces are the result of the pressure force, which varies with the radius. By applying the radial equilibrium in the control volume cavity, the derivative of the pressure with respect of the radius is obtained:

$$
\frac{d p}{d r}=\rho r C_{f_{c}}^{2} \omega^{2}
$$

Then by integrating this equation, the pressure at a specific radius of the shroud or hub can be calculated as

$$
p_{s h, h}(r)=p_{d}-\rho_{d} \omega^{2} r_{d}^{2} \frac{C_{f_{c}}^{2}}{2}\left[1-\left(\frac{r}{r_{d}}\right)^{2}\right]
$$

where $\rho$ is the fluid density, $\omega$ is the rotor speed, $r$ is the radius, subscript $d$ is the discharge, subscript $s$ is the suction, and $C_{f c}$ is the core rotation factor. The core rotation factor is difficult to estimate without an additional empirical formula. Hence, the core rotation factor is assumed.

Once the pressure distribution is calculated, the force acting on the shroud and hub can be calculated as

$$
F_{s h, h}=\sum_{i=i}^{n} p\left(r_{i}\right)_{s h, h} A(i)_{s h, h}
$$


where $A$ is the area between two discretization points.

The static force acting on the impeller can be expressed as

$$
F_{s t, i n}=\pi\left(r_{\text {seal } ; s h}^{2}-r_{s}^{2}\right) p_{s},
$$

where $p_{s}$ is the pressure between the shroud seal radius and the impeller suction.

The gas momentum $F_{\text {mom }}$ in Eq. (23) can be calculated as

$$
F_{m o m}=v_{a x, s} \dot{m}-v_{a x, d} \dot{m},
$$

where $v$ is the gas velocity inside the cavity and $m$ is the fluid flow velocity.

The balance piston $F_{p i s}$ in Eq. (23) can be expressed as

$$
F_{p i s}=\frac{\pi}{4}\left(D_{p i s}^{2}-D_{\text {seal }, h}^{2}\right) p_{s},
$$

where $D$ is the diameter of the balance piston and the seal.

Because of the thrust components acting on the shroud and hub, which are in contact on the surface at certain angles, the thrust component on the shroud and hub can be divided into two components, which are the $z$-axis (axial component) and the $x$ - and $y$-axes (lateral component). These two forces can be obtained as

$$
\begin{gathered}
F_{s h, h ; z}=F_{s h, h} \cos \theta, \\
F_{s h, h ; r}=F_{s h, h} \sin \theta .
\end{gathered}
$$

Because of the symmetrical structure of the impeller, the lateral distribution of the $y$-axis thrust component is neglected in all directions; thus, $F_{s h, h ; r}$ can be regarded as 0 .

The axial force calculated in this study neglects the balance piston as it is not included in the simulation. The calculation uses the impeller parameters shown in Table 1.

The relationships between the axial force and the rotor speed obtained using Eq. (23) are shown in Fig. 5. The axial thrust profile increases exponentially with the rotor speed. This curve characteristic demonstrates that the axial thrust is a function of pressure and rotor rotation

Table 1

Impeller parameters.

\begin{tabular}{lc}
\hline Parameter & Data \\
\hline Core rotation factor & 0.5 \\
Discharge pressure & $18.29 \mathrm{bar}$ \\
Suction pressure & $8.77 \mathrm{bar}$ \\
Density & $962.55 \mathrm{~kg} / \mathrm{m}^{3}$ \\
Mass flow & $2.16 \mathrm{~kg} / \mathrm{s}$ \\
\hline
\end{tabular}




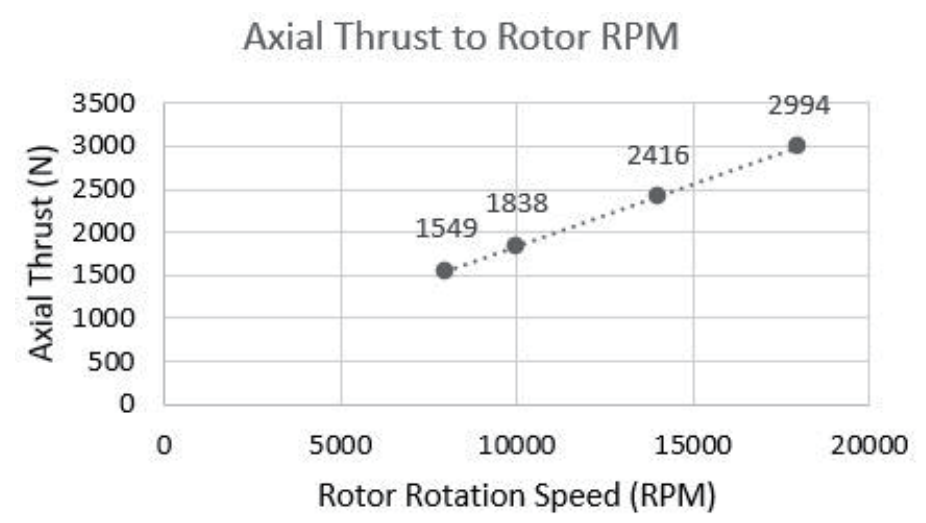

Fig. 5. Relation between axial force and rotor speed.

speed. Assuming that the axial contact face is at an angle of $90^{\circ}$ to the bearing inner raceway, then the axial contact force is equal to the axial thrust force.

Because the resonance frequencies of the axial modes are much higher than those of the lateral modes for the rotor dynamics, the rotor is considered to be rigid in the axial direction, and the dynamics are modeled using the inertia. The dynamic equation for the contact in the axial direction is $(20)$

$$
M_{r} \ddot{z}_{r}=-F_{c z}+K_{c} \Delta+C \dot{z}
$$

where $M_{r}$ is the total mass of the rotor, $z_{r}$ is the axial rotor displacement, $F_{c z}$ is the contact force in the axial direction, $K_{c}$ is the contact stiffness, which is derived from the Timoshenko contact stiffness, $\Delta$ is the axial contact deflection between the shaft and the auxiliary bearing inner raceway, $C$ is the axial damping coefficient of the auxiliary bearing, and $z$ is the axial displacement.

The contact force in the axial direction is calculated as

$$
F_{c z}=K_{c} \Delta
$$

where $K_{c}$ can be expressed as

$$
K_{c}=E \sqrt{\pi\left(r_{2}^{2}-r_{1}^{2}\right)} / 0.96\left(1-v^{2}\right)
$$

\subsection{Matrices}

\subsubsection{Stiffness matrix}

The stiffness matrix is used to calculate the support moments by using the possible nodal displacements acting on the beam and/or truss contributing to the force of each element. 


$$
K_{e}=\frac{E I_{e}}{(1+\phi) L^{3}}
$$

$K_{e}$ is the stiffness element value of the stiffness matrix. The value of $\phi$ can be defined as follows:

$$
\phi=\frac{12 E I_{e}}{G \kappa A L^{2}}=\frac{12 E I_{e}}{G \kappa \frac{\pi}{4}\left(D_{o}{ }^{2}-D_{i}^{2}\right) L^{2}} .
$$

Here, $I_{e}$ is the moment of inertia of the beam and $\kappa$ is the shear correction factor, which takes into account the non-uniform shear stress distribution over the beam cross section.

The shear correction factor for a hollow cylinder cross section can be expressed as

$$
\kappa=\frac{6(1+v)\left(1+\Re^{2}\right)^{2}}{(7+6 v)\left(1+\mathfrak{R}^{2}\right)^{2}+(20+12 v) \Re^{2}},
$$

where $v$ is the Poisson ratio and $\mathfrak{R}$ is the ratio between the inner and outer radii of the rotor's element.

\subsubsection{Mass matrix and gyroscopic matrix}

A similar concept to the stiffness matrix is also used to obtain the mass matrix and gyroscopic matrix. The mass matrix $M_{e}$ and gyroscopic matrix $G_{e}$ of an element are calculated as

$$
\begin{gathered}
M_{e}=\frac{\rho A L}{840(1+\phi)^{2}}=\frac{\rho \cdot \frac{\pi}{4}\left(D_{o}^{2}-D_{i}^{2}\right) L}{840(1+\phi)^{2}}, \\
G_{e}=\frac{-\rho I_{e}}{15 L(1+\phi)^{2}},
\end{gathered}
$$

where $\rho$ is the density of the element material, $L$ is the length of the element, $D_{o}$ is the outer diameter of the element, $D_{i}$ is the inner diameter of the element, and $I_{e}$ is the moment of inertia of the beam. The gyroscopic and damping matrices were neglected in this simulation.

\subsection{Rating life of bearing}

The touchdown bearing will act as a sacrificial device in the case of a dropdown event, which means that it will absorb the contact and friction forces and thus undergo wearing instead of the stator and rotor. The damage to the rotor will be minimized as the damaging force is absorbed by the touchdown bearing. Contact between the stator and the rotor must be avoided. 
The touchdown bearing, as mentioned above, is used as the landing pad for the stator when the system experiences a power failure or is turned off. Depending on the control of the system, the rotor can come in contact with the touchdown bearing either gradually or abruptly in the shutting down process. This means that damage to the touchdown bearing is unavoidable.

Broadly speaking, the bearing life is the period during which a bearing continues to operate and satisfy its required functions. ${ }^{(21)}$ The bearing life can be defined as the noise life, abrasion life, grease life, or rolling fatigue life, depending on the cause of the loss of bearing service. Aside from natural deterioration, bearings may fail when heat seizure, fracture, scoring of the rings, damage to the seals or the cage, or other damage occurs.

When rolling bearings are operated under a load, the raceways of their inner and outer rings and rolling elements are subjected to repeated cyclic stress. Because of the metal fatigue of the rolling contact surfaces of the raceways and rolling elements, scaly particles may separate from the bearing material. This phenomenon is called "flaking", as shown in Fig. 6. Rolling fatigue life is represented by the number of revolutions of a bearing before flaking due to stress occurs.

The basic rating life is the number of revolutions $\left(10^{6} \mathrm{rev}\right)$ of the bearing before it fails. The basic rating life function is expressed as the relation between the bearing load (as an equivalent load) and the basic load rating. The equivalent load is the hypothetical value of the load if it consists of the radial load and axial load. The basic rating life can be calculated using the following formula: ${ }^{21)}$

$$
L=\left(\frac{C}{P}\right)^{3}
$$

where $C$ is the basic load rating, which can be obtained from the manufacturer catalogue, and $P$ is the bearing load or equivalent load. The equivalent load can be calculated using

$$
P=X F_{r}+Y F_{a},
$$

where $F_{r}$ and $F_{a}$ are the radial and axial loads, and $X$ and $Y$ are the radial and axial load factors, which can be found in the manufacturer's catalogue, respectively.

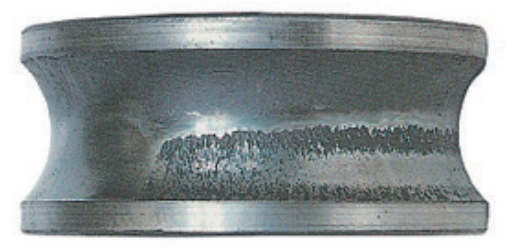

Fig. 6. (Color online) Inner raceway flaking. 


\section{Simulation}

The simulation is run using the parameters from Tables 2-4. The simulation is executed using a simulator based on MATLAB App Designer. The mathematical formulations are written in the m-file and Simulink block diagram. The simulator first calculates the initial position of the rotor using Eq. (1). The result is used to calculate the effective external forces that drive the displacement of the rotor during the rotor dropdown event.

If the displacement exceeds the air gap of the touchdown bearing, then the contact force is calculated and included in the calculation for the next iteration. There are two external forces, as mentioned in the previous section, but only the radial contact force is used for the rotor displacement calculation.

Table 2

Rotor specifications.

\begin{tabular}{lc}
\hline Parameter & Data \\
\hline Mass of rotor $(m)$ & $32 \mathrm{~kg}$ \\
Rotor speed & $18000 \mathrm{rpm}$ \\
Shaft radius $\left(R_{s}\right)$ & $29.9 \times 10^{-3} \mathrm{~m}$ \\
Rotor eccentricity $(u)$ & $1.25 \times 10^{-6} \mathrm{~m}$ \\
Air gap between rotor and auxiliary bearing & $1 \times 10^{-4} \mathrm{~m}$ \\
Rotor moment of inertia $\left(I_{r}\right)$ & $0.795 \mathrm{~kg} \cdot \mathrm{m}^{2}$ \\
\hline
\end{tabular}

Table 3

Touchdown bearing specifications.

\begin{tabular}{lc}
\hline Parameter & Data \\
\hline Inner and outer radii $\left(R_{I}\right.$ and $\left.R_{O}\right)$ & 0.03 and $0.0425 \mathrm{~m}$ \\
Number of balls $(Z)$ & 27 \\
Ball diameter $\left(D_{b}\right)$ & $7.938 \times 10^{-3} \mathrm{~m}$ \\
Auxiliary bearing stiffness $\left(K_{b}\right)$ & $1.32 \times 10^{8} \mathrm{~N} / \mathrm{m}$ \\
Young's modulus of raceway $\left(E_{i, o}\right)$ & $208 \mathrm{GPa}$ \\
Poisson ratio of raceway $\left(v_{i, o}\right)$ & 0.3 \\
Young's modulus of ball $\left(E_{b}\right)$ & $300-320 \mathrm{GPa}$ \\
Poisson ratio of ball $\left(v_{b}\right)$ & 0.26 \\
Damping support $\left(C_{S}\right)$ & $18.72 \mathrm{Ns} / \mathrm{m}$ \\
Stiffness support $\left(K_{S}\right)$ & $2.52 \times 10^{7} \mathrm{~N} / \mathrm{m}$ \\
\hline
\end{tabular}

Table 4

Parameters of finite element model of rotor.

\begin{tabular}{lc}
\hline Parameter & Data \\
\hline Number of elements & 72 \\
Number of nodes & 73 \\
Number of degrees of freedom & 2 \\
Total number of degrees of freedom & 146 \\
Rotor length & $772.87 \mathrm{~mm}$ \\
Magnetic bearing nodes & 22 and 61 \\
Auxiliary bearing nodes & 13 and 70 \\
\hline
\end{tabular}


The parameters for the rotor are calculated by the finite element method, and the rotor is divided into a number of elements. Each element is transformed into matrices and calculated by the simulator. Details of the finite element representation of the rotor are shown in Figs. 7 and 8.

The simulation is also run to compare five stiffness support designs and two damping support designs. The stiffness support designs have different thicknesses $(0.37,0.50,0.63,0.76$, and 0.88 $\mathrm{mm})$ while the other parameters are identical. The design values of the stiffness support are shown in Table 5. Then for each stiffness support design, the stiffness coefficient $\left(K_{S}\right)$ is obtained from Rao's formula ${ }^{(19)}$ as follows:

$$
K_{s}=4.8\left(E_{\text {spring }}\right) w\left(\frac{t}{p}\right) .
$$

Each stiffness coefficient from the design is incorporated into the simulator calculation. The maximum displacement of each touchdown bearing (TDB for short) for each stiffness support design is shown in Table 6 . The number of 1 or 2 after "TDB" denotes the position of the bearing $(1=$ front touchdown bearing, 2 = rear touchdown bearing $)$.

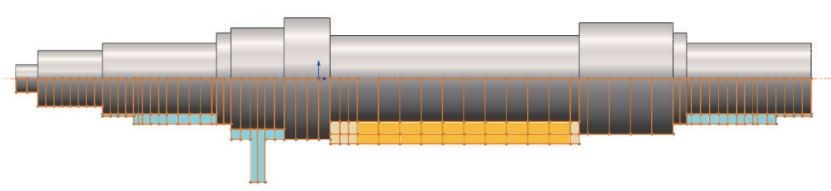

Fig. 7. (Color online) Flexible rotor with beam elements in finite element model.

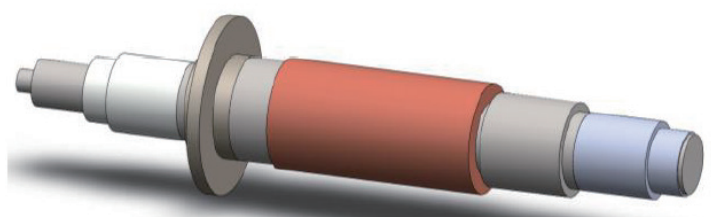

Fig. 8. (Color online) 3D model of rotor.

Table 5

Stiffness support for design parameter.

\begin{tabular}{lccccc}
\hline Specification & Design_1 & Design_2 & Design_3 & Design_4 & Design_5 \\
\hline Material & Stainless steel & Stainless steel & Stainless steel & Stainless steel & Stainless steel \\
\hline Diameter $(\mathrm{mm})$ & 85 & 85 & 85 & 85 & 85 \\
\hline Width $(w)(\mathrm{mm})$ & 26 & 26 & 26 & 26 & 26 \\
\hline Pitch $(p)(\mathrm{mm})$ & 7.5 & 7.5 & 7.5 & 7.5 & 7.5 \\
\hline Thickness $(t)(\mathrm{mm})$ & 0.37 & 0.50 & 0.63 & 0.76 & 0.88 \\
\hline $\begin{array}{l}\text { Young's modulus }\left(E_{\text {spring }}\right) \\
(\mathrm{GPa})\end{array}$ & 197 & 197 & 197 & 197 & 197 \\
\hline Mass $(\mathrm{kg})$ & 0.87 & 0.87 & 0.87 & 0.87 & 0.87 \\
\hline Damping ratio $(\zeta)$ & $0.001-0.002$ & $0.001-0.002$ & $0.001-0.002$ & $0.001-0.002$ & $0.001-0.002$ \\
\hline
\end{tabular}


Table 6

Stiffness support for each design.

\begin{tabular}{lccccc}
\hline $\begin{array}{l}\text { Thickness } \\
(\mathrm{mm})\end{array}$ & $\begin{array}{c}K_{s} \text { value } \\
\left(10^{6} \mathrm{~N} / \mathrm{m}\right)\end{array}$ & \multicolumn{2}{c}{$\begin{array}{c}\text { Max. displacement } \\
\text { of TDB1 }\left(10^{-4} \mathrm{~m}\right)\end{array}$} & \multicolumn{2}{c}{$\begin{array}{c}\text { Max. displacement } \\
\text { of TDB2 }\left(10^{-4} \mathrm{~m}\right)\end{array}$} \\
\hline & & $x$ & $y$ & $x$ & $y$ \\
\hline 0.37 & 2.95 & 1.10 & 1.20 & 1.10 & 1.20 \\
0.5 & 7.28 & 1.10 & 1.20 & 1.10 & 1.20 \\
0.63 & 14.6 & 1.10 & 1.20 & 1.10 & 1.20 \\
0.76 & 25.2 & 1.00 & 1.20 & 1.00 & 1.20 \\
0.88 & 40.0 & 1.00 & 1.20 & 1.00 & 1.20 \\
\hline
\end{tabular}

\section{Results and Discussion}

Once the prerequired parameters are obtained, the simulator can begin to calculate the displacement of the rotor for the first iteration. There are two touchdown bearing joints, as can be seen from Table 4. The results for each touchdown bearing are calculated separately and are shown in Fig. 9, where the touchdown bearings are denoted as "front TDB" and "rear TDB". As shown in Fig. 9, the maximum displacement does not exceed twice the length of the air gap or the critical gap. The maximum displacements of the rotor in the $y$-axis for the front TDB and bottom TDB are 0.121 and $0.159 \mathrm{~mm}$, respectively. The displacement of the rear TDB is higher, which is assumed to be because the mass unbalance is more tilted toward the rear TDB. In this study, the unbalance force is the factor most strongly affecting the rotor movement during the rotor dropdown event.

The contact force (Fig. 10) shows values of 121 and $103 \mathrm{kN}$ for the front TDB and rear TDB, respectively. These results are due to the mass and the high rotating speed of the rotor. The mass of the rotor affects the gravity force and the unbalance force. However, because of the high rotating speed of the rotor, the unbalance force generated is very high, which in turn affects the magnitude of the contact force. This phenomenon will gradually decrease with decreasing rotating speed of the rotor due to the friction force between the rotor and the inner raceway of the bearing.

The orbit of the rotor during the rotor dropdown event is shown in Fig. 11. The rotor orbit is drawn using the rotor displacement in Fig. 9. The rotor orbit shows that the rotor did not undergo

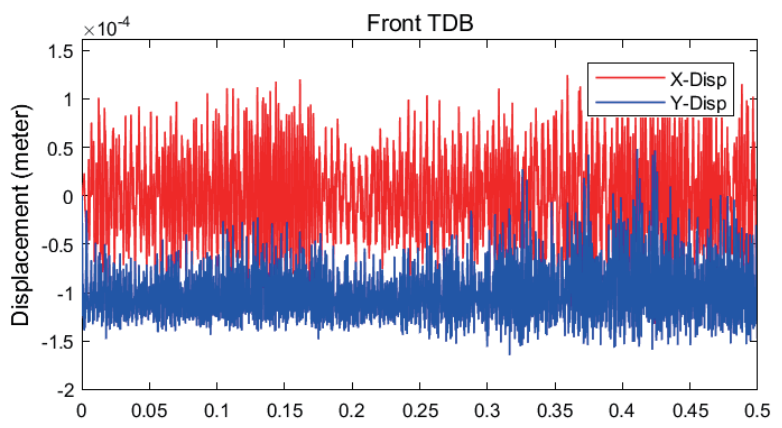

(a)

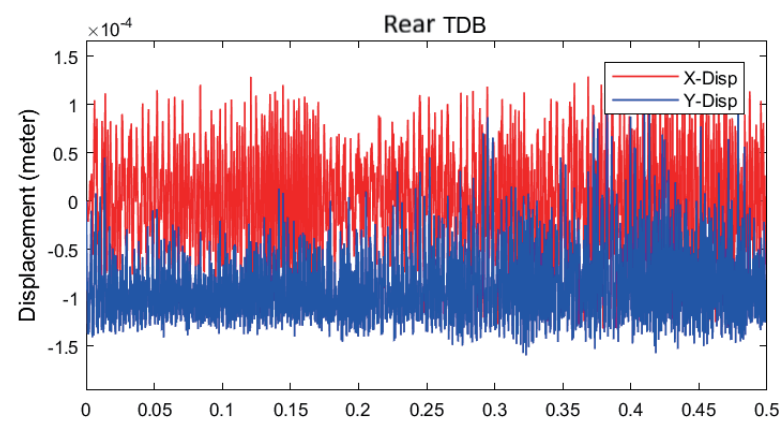

(b)

Fig. 9. (Color online) Displacement of touchdown bearings over time: (a) front TDB and (b) rear TDB. 


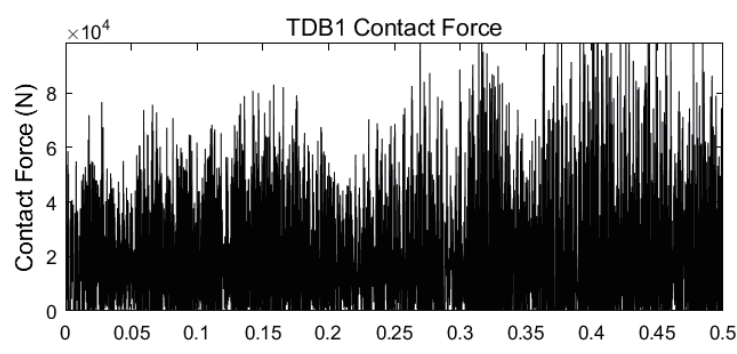

(a)

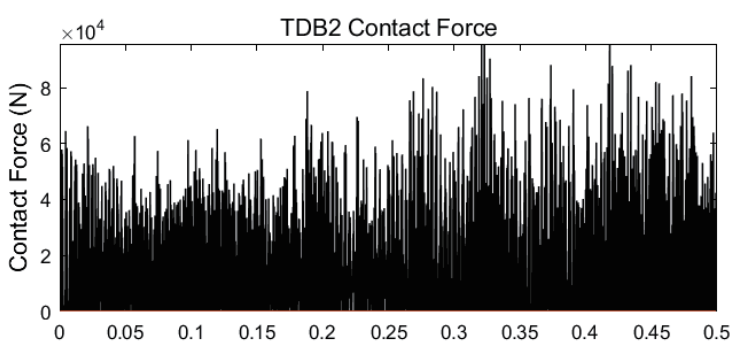

(b)

Fig. 10. Contact force of touchdown bearings: (a) front TDB and (b) rear TDB.

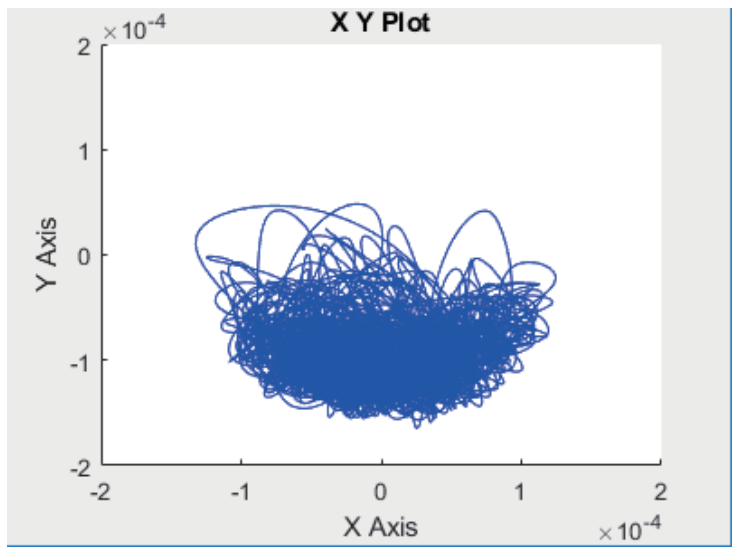

(a)

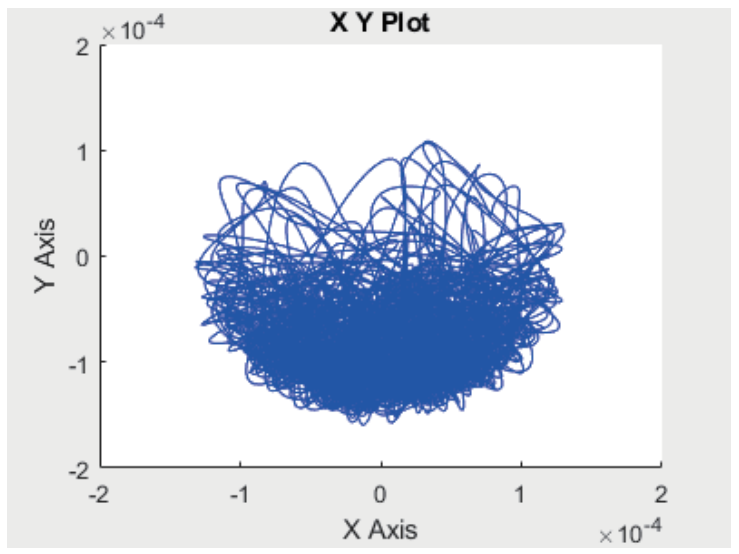

(b)

Fig. 11. (Color online) Orbits of touchdown bearing rotors: (a) front and (b) bottom.

any forward or backward whirl. The rotor is shown to bounce erratically inside the touchdown bearing. The figure also shows a circular profile on the rear TDB, which represents the inner raceway of the bearing. The higher displacement and contact force of the rear TDB is also represented by the more erratic bounce of the rotor.

Figure 11 shows the rotor orbits during the rotor drop event, where the initial rotor speed is $18000 \mathrm{rpm}$ and the stiffness and damping coefficients are $2.52 \times 10^{7} \mathrm{~N} / \mathrm{m}$ and $18.72 \mathrm{~N}$, respectively (without any support component). The resulting contact force can be seen in Fig. 12; values of $1.807 \times 10^{4}$ and $1.419 \times 10^{4} \mathrm{~N}$ were obtained on TDB1 and TDB2, respectively. Also, from Fig. 10 the maximum reduction occurred at a damping support $\left(C_{s 2}\right)$ of $18.72 \mathrm{Ns} / \mathrm{m}$, at which the contact force decreases to $1.645 \times 10^{4} \mathrm{~N}$ at TDB1 and $1.353 \times 10^{4} \mathrm{~N}$ at TDB2. Under the condition of $C_{s 1}=9.36 \mathrm{Ns} / \mathrm{m}$ the contact force also decreases, but the decrease is less than that when using $C_{s 2}$; the magnitudes of the contact force for both auxiliary bearings are $1.798 \times 10^{4} \mathrm{~N}(\mathrm{TDB} 1)$ and $1.403 \times 10^{4} \mathrm{~N}(\mathrm{TDB} 2)$. Figure 11 shows that a smaller damping coefficient results in less response from the motor. On this basis, it is assumed that a higher damping support results in less contact force but a more erratic rotor response. 
Figure 13 shows the rotor displacement in the axial direction. The axial results are smoother than the radial results because in the axial direction the rotor rotation, unbalance force, and gravity force do not directly affect the rotor movement in the $z$-axis. The rotor thrust in the $z$-axis is calculated from the fluid momentum and pressure force inside the impeller. The contact force in the axial direction is $200 \mathrm{~N}$, considerably lower than that in the radial direction as shown in Fig. 14.

The bearing life rating can be predicted using Eq. (40). By considering the load in both the axial and radial directions, the life rating for the touchdown bearing was found to be 0.07196 million revolutions. This means that the under a constant high load from the aforementioned contact force, the bearing could endure 71960 rotations before it fails. If the bearing rotation speed and contact force decrease over time, then the life rating can be expected to increase. If the rotor is rotating at its maximum speed of $18000 \mathrm{rpm}$, then the maximum lifetime of the touchdown bearing is $3.9 \mathrm{~min}$.

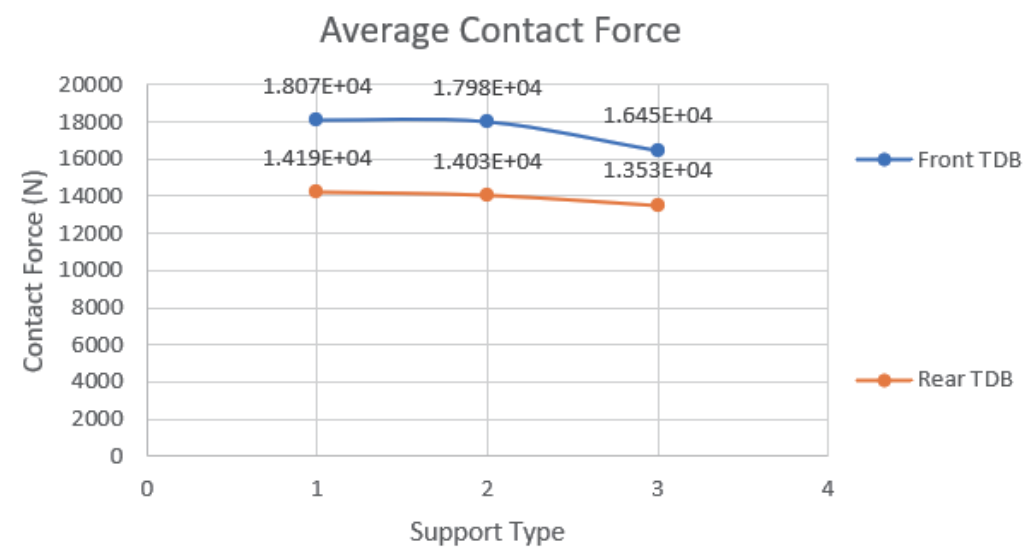

Fig. 12. (Color online) Contact force with different types of damping support.

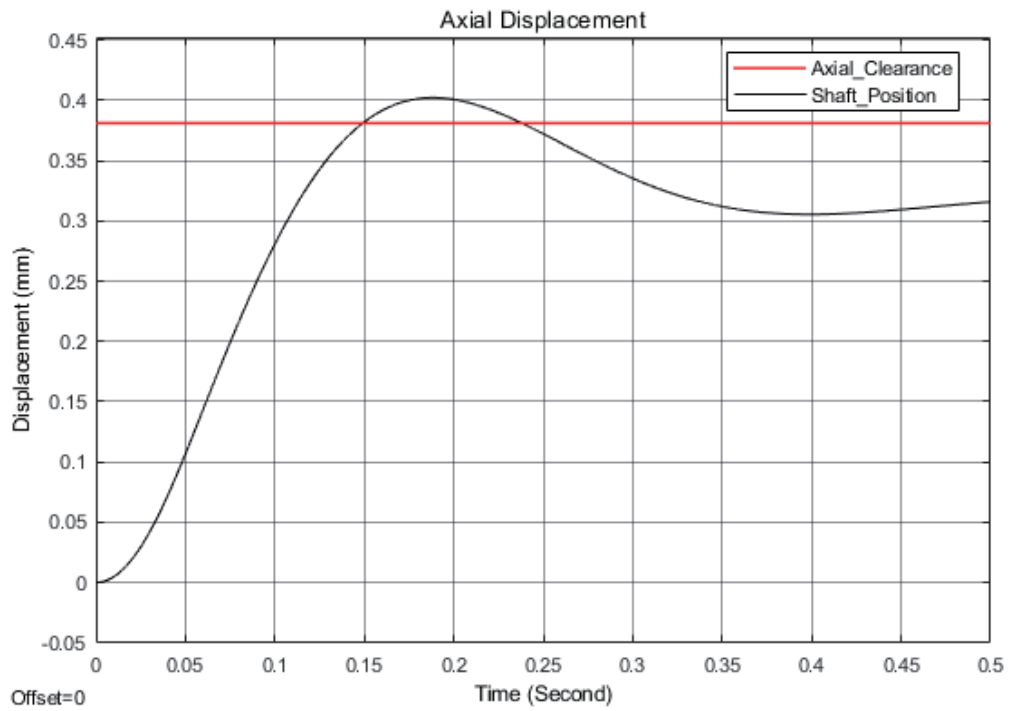

Fig. 13. (Color online) Rotor displacement in $z$-axis. 


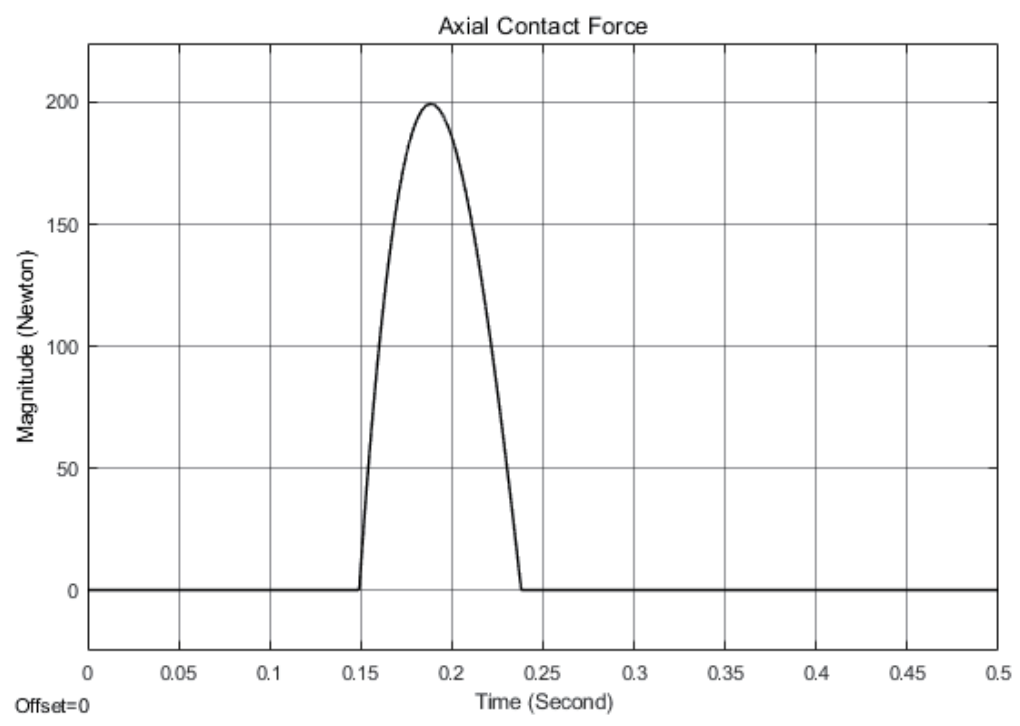

Fig. 14. Axial contact force.

\section{Conclusions}

We discussed the radial and axial contact forces acting on an auxiliary bearing. The radial contact force can be reduced by using stiffness support and damping support. The magnitude of the contact force is related to the rotor speed. When selecting a bearing, the contact force in the radial and axial directions can be used as a baseline. Furthermore, there is a large external force in the radial direction, which affects the rotor shaft movement and contact force during the rotor dropdown event. The axial direction is strongly affected by the rotor speed and the fluid force inside the impeller, which apply pressure to the impeller surface and thus apply pressure to the shaft in the axial direction. The simulation results show that the maximum contact force for application without stiffness support and damping support is $1.807 \times 10^{7} \mathrm{~N}$. By using stiffness support and damping support, the value can be reduced to $1.645 \times 10^{7} \mathrm{~N}$. The use of damping support is demonstrated to reduce the contact force and the erratic movement of the rotor on contact. The bearing rating is 71960 and the bearing lifetime is 3.9 min. During the rotor drop event, the bearing rating and bearing lifetime increase gradually due to the gradual loss of rotor speed and the decrease in contact force. The results of the simulation can be applied to design and for further improvement of the mechanics and control of auxiliary bearings in AMB systems.

\section{Acknowledgments}

The authors would like to acknowledge financial support from Industrial Technology Research Institute, Taiwan (NCUT-17-TER-027). 


\section{References}

1 P. Francis and Marchand Jr: Proc. ASME Int. Gas Turbine and Aeroengine Congress and Exhibition 4 (1997) 20.

2 J. Wilkes, G. Vannini, J. Moore, and D. Ransom: Proc. ASME Turbo Expo 7B (2013) 15.

3 M. M. Pewekar, A. G. Potawad, M. R. Pujari, and R. R. Rane: Analysis of Active Magnetic Bearing, Bachelor Thesis, University of Mumbai (2008).

4 J. Cao, T. Dimond, P. Allaire, and S. Dousti: Proc. Int. Conf ASME Turbo Expo (2016).

5 C. A. Fonseca, I. F. Santos, and H. I. Weber: J. Sound Vib. 394 (2017) 82.

6 S. Zeng: Proc. The Institution of Mechanical Engineers Part I: Int. J. Sound Vib. 394 (2003) 82.

7 J. Ritonja, B. Polajžer, D. Dolinar, B. Grčar, and P. Cafuta: Proc. the 29th Chinese Control Conf. (2010) 4-10.

8 C. Y. Chen, C. C. Liu, A. Yuliane, and Y. D. Kuan: Int. Symp. Magn. Bearing (2018).

9 G. Schweitzer: Proc. the Institution of Mechanical Engineers Part I: Int. J. Syst. Control Eng. 219 (2005) 83.

10 C. Liu, K. Zhang, and R. Yang: Int. J. Mech. Mach. Theory 42 (2007) 183.

11 J. C. Ji, C. H. Hansen, and A. C. Zander: Int. J. Intell. Mater. Syst. Struct. 19 (2008) 71.

12 J. W. Zu and Z. Ji: Int. J. Eng. Gas Turbine Power 124 (2002) 303.

13 E. N. Cuesta, L. U. Medina, V. R. Rastelli, N. I. Montbrun, and S. E. Diaz: Proc. ASME Turbo Expo (2003).

14 J. I. Inayat-Hussain: Int. J. Mech. Mach. Theor. 45 (2010) 51.

15 H. Ecke: Proc. Euromech Colloquium (1998) 79-88.

16 T. A. Harris and M. N. Kotzalas: Rolling Bearing Analysis: Essential Concepts of Bearing Technology (Taylor \& Francis Group, New York, 2007) 5th ed.

17 Karkkainen, J. Sopanen, and A. Mikkola: Research Report, Lappeenranta University of Technology (2006).

18 J. W. Smith: IEEE Ind. Appl. Mag. 8 (2002) 74.

19 S. Rao: Mechanical Vibrations (Prentice Hall, New Jersey, 2010) 5th ed., pp. 18-20.

20 E. Munari, M. Morini, M. Pinelli, K. Brun, S. Simons, and R. Kurz: Int. J. Eng. Gas Turbine Power 140 (2017) 012602.

21 NSK Bearing International: http:/www.nsk.com/services/basicknowledge/technicalreport/ (accessed April 2019).

\section{About the Authors}

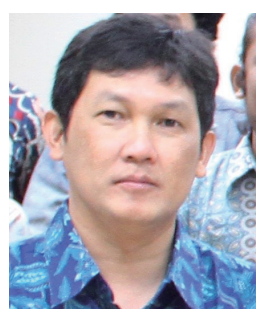

C. Bambang Dwi Kuncoro received his diploma in electrical engineering from Polytechnic of Bandung Institute of Technology (ITB), Indonesia, in 1993 and his bachelor's and master's degrees in electrical engineering from ITB in 1999 and 2002, respectively. He received his doctoral degree in precision manufacturing from Graduate Institute of Precision Manufacturing, National Chin-Yi University of Technology (NCUT), Taiwan, in 2020. Since 2020, he has been a professor at Department of Refrigeration, Air Conditioning and Energy Engineering at NCUT. His research interests include sensor integration, embedded systems, control and monitoring applications, wireless sensor networks, wireless power transfer, and renewable energy. (bkuncoro@ncut.edu.tw)

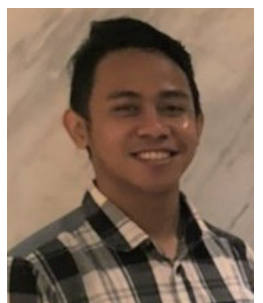

Rafael Oscar received his bachelor's degree from Department of Refrigeration and Air Conditioning Engineering at Politeknik Negeri Bandung (Polban), Indonesia, in 2017 and his master's degree from Department of Refrigeration, Air Conditioning and Energy Engineering at National Chin-Yi University of Technology (NCUT), Taiwan, in 2020. Since 2020, he has been a trainee system engineer at Kuen Ling Refrigerating Machinery Co., Ltd., Indonesia. (rafaeloscar375@gmail.com) 


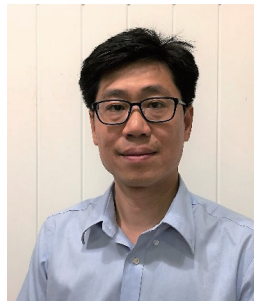

Chung-Che Liu received his bachelor's degree in aeronautical engineering from the University of Tamkang in 1991 and his master's degree from the National Institute of Power Machinery of Tsinghua University in 1993. He majored in subjects such as heat flow, aviation, and internal combustion engines. He entered the Institute of Green Energy and Environment of Industrial Technology Research Institute, Taiwan, in 1993. He is mainly engaged in research on high-efficiency central air-conditioning chillers, specializing in thermodynamic cycle analysis, heat exchanger design, and refrigerant system control.

(ccliu@itri.org.tw)

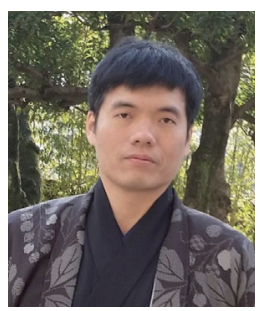

Chao-Yun Chen received his bachelor's and master's degrees in electrical engineering from Da-Yeh University, Changhua, Taiwan, in 2004 and 2006, respectively, and a Ph.D. degree in electrical engineering from National Cheng Kung University, Tainan, Taiwan, in 2012. He is a senior research fellow in Industrial Technology Research Institute, Taiwan. His research interests include motion control, adaptive control, robot manipulators, magnetic bearings, and rotor dynamics. (cychen@itri.org.tw)

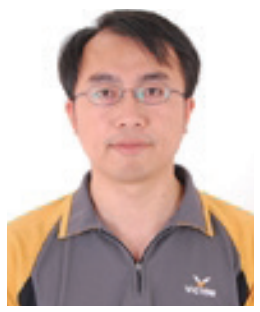

Kuo-Shu Hung received his Ph.D. degree in mechanical engineering from Tatung University, Taipei, Taiwan, in 2006. He is a senior research fellow in Industrial Technology Research Institute, Taiwan. His research interests include magnetic compressor design and computational fluid dynamics.

(kshung@itri.org.tw)

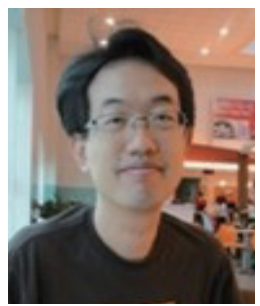

Yean-Der Kuan is a distinguished professor and former chairman (2013/022019/01) of the Department of Refrigeration, Air Conditioning and Energy Engineering at National Chin-Yi University of Technology (NCUT), Taichung, Taiwan. He received his Ph.D. degree from the Department of Mechanical and Aerospace Engineering at the University of Missouri, USA, in 2000. Currently, he is also the director of Taiwan Society of Heating, Refrigeration and Air Conditioning, director of Taiwan Energy Association, director of Taiwan Association for Hydrogen Energy and Fuel Cell, and a member of the American Society of Heating, Refrigerating, and Air Conditioning. His research interests include the fields of energy saving, renewable energies, and air conditioning components and systems.

(ydkuan@ncut.edu.tw) 